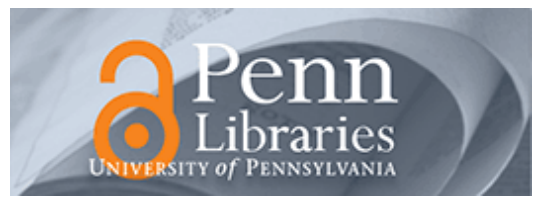

University of Pennsylvania

ScholarlyCommons

Marketing Papers

Wharton Faculty Research

2005

\title{
Living, and Thinking about It: Two Perspectives on Life
}

Daniel Kahneman

Jason Riis

University of Pennsylvania

Follow this and additional works at: https://repository.upenn.edu/marketing_papers

Part of the Cognition and Perception Commons, Cognitive Psychology Commons, Marketing Commons, and the Social Psychology Commons

Recommended Citation (OVERRIDE)

Kahneman, D. \& Riis, J. (2005). Living, and Thinking about It: Two Perspectives on Life. In Huppert, F.A., Baylis, N., \& Keverne, B. (Eds.), The Science of Well-Being, 285-304. Oxford University Press.

This paper is posted at ScholarlyCommons. https://repository.upenn.edu/marketing_papers/405

For more information, please contact repository@pobox.upenn.edu. 


\title{
Living, and Thinking about It: Two Perspectives on Life
}

\author{
Abstract \\ Introduction It is a common assumption of everyday conversation that people can provide accurate \\ answers to questions about their feelings, both past (e.g. 'How was your vacation?') and current (e.g. \\ 'Does this hurt?'). Although the distinction is mostly ignored, the two kinds of questions are vastly \\ different. Introspective evaluations of past episodes depend on two achievements that are not required \\ for reports of immediate experience: accurate retrieval of feelings and reasonable integration of \\ experiences that are spread over time. The starting point for this chapter is that the retrieval and the \\ temporal integration of emotional experiences are both prone to error, and that retrospective evaluations \\ are therefore less authoritative than reports of current feelings. We first consider the dichotomy between \\ introspection and retrospection from several perspectives, before discussing its implications for a \\ particular question: how would we determine who is happier, the French or the Americans?

\section{Disciplines} \\ Business | Cognition and Perception | Cognitive Psychology | Marketing | Social Psychology
}




\title{
Chapter 11
}

\section{Living, and thinking about it: two perspectives on life}

\author{
Daniel Kahneman and Jason Riis
}

\section{Introduction}

It is a common assumption of everyday conversation that people can provide accurate answers to questions about their feelings, both past (e.g. 'How was your vacation?') and current (e.g. 'Does this hurt?'). Although the distinction is mostly ignored, the two kinds of questions are vastly different. Introspective evaluations of past episodes depend on two achievements that are not required for reports of immediate experience: accurate retrieval of feelings and reasonable integration of experiences that are spread over time. The starting point for this chapter is that the retrieval and the temporal integration of emotional experiences are both prone to error, and that retrospective evaluations are therefore less authoritative than reports of current feelings. We first consider the dichotomy between introspection and retrospection from several perspectives, before discussing its implications for a particular question: how would we determine who is happier, the French or the Americans?

\section{Two selves}

An individual's life could be described - at impractical length-as a string of moments. A common estimate is that each of these moments of psychological present may last up to 3 seconds, suggesting that people experience some 20000 moments in a waking day, and upwards of 500 million moments in a 70 -year life. Each moment can be given a rich multidimensional description. An individual with a talent for introspection might be able to specify current goals and ongoing activities, the present state of physical comfort or discomfort, mental content, and many subtle aspects of subjective experience, of which valence is only one. What happens to these moments? The answer is straightforward: with very few exceptions, they simply disappear. The experiencing self that lives each of these moments barely has time to exist.

When we are asked 'how good was the vacation', it is not an experiencing self that answers, but a remembering and evaluating self, the self that keeps score and 
maintains records. Unlike the experiencing self, the remembering self is relatively stable and permanent. It is a basic fact of the human condition that memories are what we get to keep from our experience, and the only perspective that we can adopt as we think about our lives is therefore that of the remembering self. For an example of the biases that result from the dominance of the remembering self, consider a music lover who listens raptly to a long symphony on a disk that is scratched near the end, producing a shocking sound. Such incidents are often described by the statement that the bad ending 'ruined the whole experience'. But, in fact, the experience was not ruined, only the memory of it. The experience of the symphony was almost entirely good, and the bad end did not undo the pleasure of the preceding half hour. The confusion of experience with memory that makes us believe a past experience can be ruined is a compelling cognitive illusion. The remembering self is sometimes simply wrong.

The approach to well-being that we describe here emerged from an empirical study of the rules that govern the remembered scores of such episodes as brief emotional films (Fredrickson and Kahneman 1993), painful medical procedures (Redelmeier and Kahneman 1996), or annoyingly loud sounds (Schreiber and Kahneman 2000). The principal finding of this line of research was that episodes are scored by the value of a representative moment, which can be the feeling associated with its end or a weighted average of the ending moment and the most intense one- this has been called the peak/end rule. As implied by the peak/end rule, the evaluation of episodes is remarkably insensitive to their durations - this phenomenon has been called duration neglect.

The rules of evaluative memory can lead to bad choices. For example, subjects in a study by Kahneman et al. (1993) were exposed to two cold-pressor episodes and then given a choice of which of them to repeat on a third trial. In the 'short' episode, they held a hand in water at $14^{\circ} \mathrm{C}$ for 60 seconds, experiencing substantial pain. The 'long' episode lasted 90 seconds. The first 60 seconds were identical to the short episode; over the final 30 seconds the temperature was gradually raised to $15^{\circ} \mathrm{C}$, still unpleasant but less so. From the point of view of the experiencing self, the long trial is clearly worse. For the remembering self, however, the peak/end rule implies that the added period of diminishing pain makes the memory of the long trial less aversive. The choice to repeat the inferior experience reflects the misguided preferences of the remembering self.

\section{Constituents of well-being}

The exclusive concern with the remembering self is a notable feature of well-being research. The vast body of literature devoted to subjective well-being is dominated by the questions, 'How satisfied are you with your life as a whole?' and 'How happy are you these days?' The happiness question explicitly requires the respondent to retrieve, integrate, and evaluate memories. The life satisfaction question involves 
evaluations that are even more remote from actual experience. In a different vein, researchers who prefer a eudaemonic conception of well-being also measure it by consulting stable aspects of the self-concept, such as purpose in life ( $\mathrm{Ryff}$ and Keyes 1995), self-actualization (Ryan and Deci 2000), and optimism (Seligman 2002). The well-being of the experiencing self has been the object of much less research (but see Csikszentmihalyi and Larson 1984; Riis et al. 2005; Stone et al. 1999). In the remainder of this chapter we explore some conceptual and methodological issues that arise in measuring experienced well-being, and present some preliminary results and conclusions.

The hybrid concept of well-being that is illustrated in Fig. 11.1 distinguishes two components, which are labeled 'experienced well-being' and 'evaluated well-being'. Both are subjective, and both refer to a period of time that may be measured in days or months. The first component includes the statistics of the momentary affective states experienced during the reference period. The second component includes global subjective evaluations of one's life during the same period. The two components are not independent. Subjective evaluations are strongly influenced by emotional experiences - an individual who has recently experienced mostly negative affect is unlikely to describe herself as very happy or satisfied. Conversely, subjective evaluations of the state of one's life certainly have affective consequences, at least while the thoughts of these evaluations are active. The two components of well-being are therefore expected to be correlated, but they are distinct, empirically as well as conceptually.

We expect that, in many situations, measures of experienced well-being and of satisfaction with life or with some aspect of it (work, marriage) may be highly

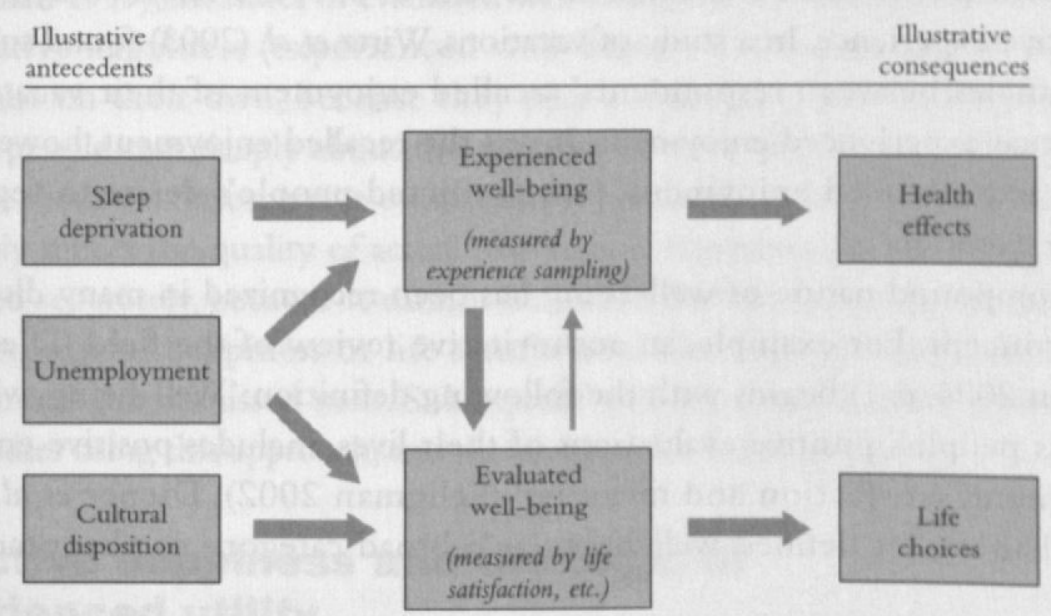

Fig. 11.1 Examples of different antecedents and consequences of experienced and evaluated well-being. Thickness of arrows indicates strength of the relationship. Not all relationships are shown. 
correlated, and may share the same pattern of antecedents and consequences. Experienced well-being will be considered primary in such cases. When routine mood and general life satisfaction correspond closely, the conclusion that mood is the major determinant of life satisfaction is more plausible than the claim that people's routine moods are mainly determined by their general view of their lives.

Of course, the point of distinguishing experience from evaluation in well-being is that the two are not always in perfect correspondence. Figure 11.1 presents several hypotheses about factors that influence one of the constituents of well-being more than the other. For example, we suggest that a temporary state of anemia or sleep deprivation has a direct effect on affective experience, but only an indirect effect on self-reported happiness and life satisfaction. At the other extreme, we propose that the low level of life satisfaction among the French (who report much lower life satisfaction than, for example, Americans and Danes) could be due entirely to the rules that govern evaluations and their expressions in the French culture. We know of no evidence that the actual affective experience of the French is generally worse than that of the Americans or the Danes. ${ }^{1}$ Finally, some life circumstances have a direct impact on both experience and evaluation; we list unemployment as a likely example.

The occasional dissociation of evaluated from experienced well-being is of modest interest on its own. The significance of the distinction between affective experience and life evaluations mainly depends on whether they have different consequences. As the relevant data have not been collected, we do not know the answer. However, it is a plausible speculation that the stress of negative affective experiences may have a direct cumulative effect on health (Marmot 2004; Sapolsky 1999). On the other hand, a decision to seek therapy or get a divorce could be a direct consequence of an evaluation of the state of one's life, related only indirectly to affective experience. In a study of vacations, Wirtz et al. (2003) found substantial discrepancies between respondents' recalled enjoyment of their vacation and their actual experienced enjoyment. It was the recalled enjoyment, however, and not the experienced enjoyment, that predicted people's desire to repeat the vacation experience.

The compound nature of well-being has been recognized in many discussions of the concept. For example, an authoritative review of the field (Diener and Seligman 2004, p. 1) begins with the following definition: 'Well-being, which we define as people's positive evaluations of their lives, includes positive emotions, engagement, satisfaction and meaning' (Seligman 2002). Diener et al. (1999, p. 277) had earlier defined well-being as 'a broad category of phenomena that

1 A dissociation of the kind that we propose was found in the only published study looking directly at this type of question. Oishi (2002) reported that Japanese-American students report lower levels of well-being than white American students in retrospective (evaluative) reports, but equivalent levels in online (experiential) reports. 
includes people's emotional responses, domain satisfactions, and global judgments of life satisfaction'. The lists of constituents of well-being in both definitions are related to the distinction drawn in Fig. 11.1: positive emotions belong to experienced utility; meaning and life satisfaction belong to evaluation. These representative definitions of well-being clearly imply the existence of components that are at least partly independent of each other. Nevertheless, the dominant practice in well-being research effectively ignores the issue, and continues to treat the determinants and consequences of happiness as if it were a unitary concept.

The simplifying assumption that well-being is unitary is implicitly invoked in many discussions of well-being. It plays a particularly important role in the common practice of using both national differences and individual differences in accounts of individual well-being (Diener and Seligman 2004; Diener and Suh 1999; Frey and Stutzer 2000; Helliwell 2003; Layard 2005). This practice can only be justified if the phrase 'happier than' has a similar meaning in the contexts of 'John is happier than Peter; he scores higher by 1 point on the happiness scale' and 'the Americans are happier than the French; they score higher by 1 point on the happiness scale'. Figure 11.1 represents the hypothesis that happiness may have quite different meanings in these contexts. Specifically, we agree that it is reasonable to infer from the difference in reported life satisfaction that John probably experiences more happiness than Peter, but we know of no evidence that would justify a similar inference about the Americans and the French.

The main operational conclusion from this discussion is that experienced and evaluated well-being should both be measured, and that the measures should be explicitly separated. Contrary to a position that one of us espoused earlier (Kahneman 1999), measures of evaluated well-being are not simply flawed indicators of objective happiness (experienced well-being). Evaluation and memory are important on their own, because they play a significant role in decisions, and because people care deeply about the narrative of their life. On the other hand, an exclusive focus on retrospective evaluations is untenable if these evaluations do not accurately reflect the quality of actual experience. Experienced well-being must be measured separately, because it cannot be inferred with adequate precision from global reports of happiness or life satisfaction. The logical foundations of this measurement are discussed next. Subsequent sections describe preliminary results from studies using this approach, and sketch ideas for future research.

\section{Objective happiness and the logic of experienced utility}

The approach to experienced well-being that we present here extends an earlier analysis of Bentham's notion of utility (Kahneman 1999, 2000; Kahneman et al. 1997). Bentham's concept was labeled experienced utility, to distinguish it from the 
usage now current in decision theory and in economics, where utility is interpreted as decision utility, and is inferred from choices and applied to explain choices. In Bentham's classic usage, utility refers to the hedonic dimension of experience (Bentham 1789/1948): each moment is characterized by the quality and intensity of pleasure or pain. The utility of more complex events is described by additional attributes, including intensity, duration, certainty, and fecundity. Bentham's concept of utility is a good starting point for our enquiry.

The basic element of experienced utility is moment utility, the true answer to the question: 'how good or bad is your experience now?' Meaningful outcomes, however, last more than a moment. A useful measure of experienced utility must be applicable to temporally extended outcomes, but it must be derived from measurements of moments according to some logical rules. One of these rules is temporal monotonicity: adding an extra period of pain to an episode of pain can only make things worse. As we mentioned earlier, judging episodes of pain by the peak and the end leads to violations of monotonicity, both in retrospective evaluations and in choices. The conclusion from that research was that the scores kept by the remembering self (they have been called 'remembered utilities') violate logic.

A formal analysis of experienced utility was offered by Kahneman et al. (1997), who examined the requirements for deriving an adequate measure of the total utility of an episode from reports of moment utility over its duration. They first identify three requirements that the measure of moment utility must satisfy: (1) reports of the sign of experience (positive or negative) can be trusted; (2) reports of the positive or negative intensity of the experience satisfy the conditions of ordinal measurement; and (3) reports of experience are interpersonally comparable. Next, two normative conditions identify factors that should not influence evaluations of the total utility experienced over a period of time: (4) separability: the order in which moment utilities are experienced is not relevant to total utility; and (5) time neutrality: all moments have equal weights. If these five conditions hold, then cumulative distributions of moment utility over time provide a measurement of total utility that is adequate for most research purposes. Except for the rare cases in which the cumulative distributions cross, the mean (or the median) of the distribution of moment utility is an ordinal measure of total utility that can be compared across situations, people, and populations (Kahneman 2000). ${ }^{2}$

2 Additional conditions must be satisfied to achieve a cardinal measurement of utility in terms of time (Broome 1991; Kahneman et al. 1997), in which total utility is the temporal integral of the rescaled utility measure. This is the level of measurement that is assumed when states of health are specified in terms of QALYs (quality-adjusted life years), e.g. when the judgment is made that 10 years of survival on dialysis have the same utility as 8 years of survival in perfect health. 
The formal analysis establishes, at least in principle, the feasibility of a measure of experienced well-being (objective happiness), as proposed in Fig. 11.1. Specifically, it shows how a global measure of the well-being of individuals or of populations can be obtained by using the experience-sampling method (ESM; Csikszentmihalyi 1994; Stone et al. 1999). Participants in ESM studies carry a hand-held computer that calls them at random moments during the waking day to answer questions about their current situation and their current feelings. These reports of momentary subjective state provide an ordinal measure of moment utility. The cumulative distribution of these moment utilities can be used to compare the well-being of populations that differ in their life circumstances. For example, we could assess the proportion of time that the rich and the poor spend at a utility level of 6 , or below 3 on a 6-point scale. This concept of well-being has been called objective happiness (Kahneman 1999, 2000), because the global evaluation of happiness is constructed according to an objective rule, although it is ultimately based on subjective reports of the experience of moments. In terms of the distinction that was drawn earlier, objective happiness is moment-based, and draws only on immediate introspection; unlike other measures of well-being, it does not involve retrospection at all. The remainder of this chapter deals with theoretical and empirical aspects of objective happiness, and compares it with other approaches to the measurement of well-being. First, we consider some objections to both the feasibility and the appropriateness of this approach to well-being.

\section{Is moment utility unidimensional?}

An immediate difficulty is that the method, at least in its simplest form, depends on a single measure of moment utility as a building block. We must be willing to believe that people are capable of applying the scale coherently to headaches, pangs of guilt, beautiful music, and the pleasure of hoping for a better future - and that they are also capable of appropriately weighting such experiences whenever several of them occur at the same moment. This may be too much to ask from untrained introspection. It is worth noting, however, that the standard procedure in which people are asked to report a single value of happiness or life satisfaction implicitly involves similar assumptions about the ability to compare and combine heterogeneous experiences.

The best rationale for a single dimension of experienced utility may well be its relation to decision utility, and to the fundamental dichotomy of approach and avoidance. Intensities of positive and negative utilities may be difficult to compare across categories of experiences, but the basic distinction between good and bad moments - the sign of the utility measure-is easier to determine. Choices between approach and avoidance occur frequently in the lives of humans and other animals, and conflicting tendencies must be weighed and resolved. The ability to resolve such conflicts implies that a common currency is used to combine and 
compare the values of different experiences (Cabanac 1992; Montague and Berns 2002; Shizgal 1999). Cabanac boldly suggested that this currency is pleasure.

The idea of anchoring the concept of experienced utility in approach and avoidance suggests a measure: respondents can be asked to indicate whether they feel impatient for their current situation to end, or would prefer for it to continue (Kahneman et al. 2004b). This measure of well-being is far from perfect-it reflects expectations about the next state as well as a response to the current state. When aggregated over a long period of time, however, the average of the momentary preference for continuing or stopping is an appealing measure: it identifies well-being with the extent to which individuals live their lives in a state of wishing for the present to extend, as against wishing they were somewhere else-or not caring one way or the other. Notably, this measure applies equally well to eudaemonic and to hedonic states, to intense absorption ('flow') and to sensory pleasure, to boredom and to pain.

Although the present discussion assigns a privileged role to the elicitation of action tendencies, we do not recommend that moment utility be measured by a single question. Affective experience varies along many dimensions, and moments can be good or bad in many different ways: we can be angry, afraid, sad, bored, humiliated, wasting time; we can be proud, serene, involved, in control, pleased, purposeful, or affectionate. Each of these distinct feelings has its own pattern of causes and consequences, which are likely to be of interest to the student of well-being. A single summary measure of objective happiness is useful, but it is not all we want to know about the life of the experiencing self.

The preceding discussion has assumed that moment utility is measured by collecting introspective reports, but this restriction is not necessary. Appropriately validated physiological measures of moment utility could be used instead, and may have important advantages (Stone et al. 1999). The most promising physiological indicator of momentary affect is the prefrontal cortical asymmetry in the electroencephalogram (EEG), which has been extensively validated by Davidson and his team as a measure of the balance of positive and negative feelings, and of the relative strength of tendencies toward approach or avoidance (Davidson 1992, 2004; Sutton and Davidson 1997). A portable measuring instrument is not yet available, but is technically feasible. When success is achieved, Davidson's technique will be a candidate for a continuous and non-intrusive indicator of moment utility. As we show in a subsequent section, even the existing laboratory measure could be useful in validating and correcting verbal reports of experienced well-being.

\section{The rationale for separability and time neutrality}

Next, we discuss some common misunderstandings of the assumptions of separability and time neutrality. By separability, total utility is independent of the order in which moment utilities are experienced. This assertion appears to 
contradict the compelling intuition that the sequencing of experiences does matter. However, the source of the apparent conflict is a failure to distinguish moment utilities from the events that give rise to those utilities. The order of events certainly matters to the total utility of a sequence, but the separability assumption only asserts that the order of utilities does not. The order of events matters when their utilities are affected by it, which is a common occurrence. For example, the order in which a rich lunch and a strenuous tennis game are experienced surely makes a difference to total utility, because the tennis game will be much less enjoyable soon after lunch, but this is not a violation of separability in the present sense.

The order in which events occur also matters when their experienced utility is influenced by comparison processes. For example, we recognize that, if an individual wins the lottery twice in successive months, total utility will be higher if the first win is $\$ 1000$ and the second $\$ 1000000$ than if the order is reversed. Clearly, the joy of winning $\$ 1000$ is attenuated in the context of the larger sum. A much larger amount - perhaps $\$ 100000$ - might be required in that sequence to match the utility of an unexpected win of $\$ 1000$ when it occurs first. Assuming for simplicity that the utility of the million win is not affected by order, separability implies that the sequences $(\$ 1000-\$ 1000000)$ and $(\$ 1000000-\$ 100000)$ have the same total utility, because the constituent utilities in the two sequences are the same. This does not appear unreasonable. For another illustration of the separability of utilities, consider the life of a 60 -year-old woman, of whom it is only known that she experienced very different levels of happiness in her thirties and in her forties. We see no compelling reason for the evaluation of her life as a whole to depend on the order of these experienced utilities. As these examples show, separability is quite plausible for sequences specified in terms of utilities.

The assumption of time-neutrality asserts that the contribution of a moment to the utility of a longer episode is determined only by the utility of that moment, not by its content. Note that time neutrality does not assert that all moments of life are equally significant or important. Privileged moments acquire special significance by affecting the utility of other moments. For example, the event of graduating from college is both anticipated for a long time and frequently recalled after it happens, thereby inducing experienced utility both early and late. Graduation may also bring about changes in the individual's activities, circumstances, and self-image, and influence experienced utility in these ways. But the utility of the moment of graduation itself is not privileged in the assessment of total utility. For the purpose of this assessment, it is just another moment.

Time neutrality is essential for the present approach, in which experienced well-being is measured by the temporal distribution of moment utility. The focus on the duration of experiences calls attention to the allocation of time as one of the more practical ways to improve experienced well-being. Competing views of 
well-being have one feature in common: in every conception some activities and mental states are considered better than others-pleasure is better than pain; intense absorption in contemplation or in activity is more valued than lethargic emptiness; intense communion with others is valued more than loneliness and hostility. Other things being equal, well-being is increased by spending more time in the good states and less time in bad or empty states. This formulation holds whether the good state is defined by positive affect or by intense engagement in a task or in a spiritual pursuit. Time is the ultimate finite resource of life, and finding ways to spend it well is a worthy objective both at the individual level and at the level of a social policy that is concerned with human well-being.

\section{Measuring experienced well-being: the day reconstruction method}

The application of experience sampling to measure and compare the well-being of populations is technically feasible but quite impractical, because the method places a high burden on respondents and severe constraints on recruitment and compliance. In an attempt to overcome this difficulty, Kahneman et al. $(2004 a, b)$ developed the day reconstruction method (DRM), which combines a time-budget study with a technique for recovering detailed information about specific experiences from the previous day. The DRM is intended to reproduce the information that would have been collected by measuring the experience immediately, as in the experience sampling method, and to do so more efficiently. The method allows a characterization of the experienced utility associated with the diverse settings and activities of people's lives, and it also provides a measure of how they allocate their time among settings, activities, and partners in social interactions.

The DRM employs a structured questionnaire that elicits a detailed description of a particular day in the respondent's life. The method is based on research indicating that accurate retrospective reports of affect can be achieved by encouraging retrieval of specific and relatively recent episodes (Robinson and Clore 2002). Respondents first revive memories of the previous day by constructing a short diary consisting of a sequence of episodes. Next the respondents describe each episode in detail by indicating: (1) when the episode began and ended; (2) what they were doing; (3) where they were; (4) persons with whom they were interacting; and (5) how they felt on multiple affect dimensions (in each case on a scale ranging from 0 (not at all) to 6 (very much)).

An illustrative study using the DRM was conducted, in which 1018 working women in Texas participated (Kahneman et al. 2004b). The central conclusions of the study are as follows.

1 Most people report themselves in at least a moderately good mood most of the time. Negative affect (anger, frustration, depression, feeling criticized) is reported only $34 \%$ of the time. However, people often describe themselves as 
tired $(76 \%$ of the time above 0$)$ and also, at least to some degree, as 'impatient for it [the current episode] to end' ( $55 \%$ of the time above zero).

2 The overall distributions of ratings, as well as the diurnal rhythms (which are quite pronounced), observed with the DRM replicate the results of prior research using experience sampling. This finding is particularly important, because the DRM is explicitly intended to provide a more efficient substitute for experience sampling.

3 Any individual's affective state varies substantially in the course of the day, depending on the activity in which he or she is engaged, as well as on the people with whom he or she interacts. The mean level of enjoyment reported, on a 0-6 scale of 'enjoying myself', was 4.68 for episodes in which the respondents socialized with friends, 2.97 when they were commuting alone, and 2.15 when the only activity recorded was interacting with one's boss.

4 Some general aspects of the respondents' circumstances had a substantial effect. For example, the mean enjoyment at work was 2.88 for respondents who described their work situation as involving high time pressure, and 3.96 for those who reported low time pressure.

5 Individual differences were also large: the standard deviation of the mean level of enjoyment reported over the entire day was 1.58 . Some individual characteristics of the respondents were strongly associated with their reports of mood. Respondents who reported that their general sleep quality was 'very good' had a mean enjoyment level of 4.05 over the entire day, which contrasts with the value of 2.80 for respondents whose sleep quality was said to be 'very bad'.

6 In contrast to the large effects of personality, immediate circumstances, and current activities, more general features of individuals' life situations had relatively small effects. For example, the correlation between income and mean enjoyment over the day was 0.05 , which is significantly lower than the correlation of 0.20 between income and general life satisfaction in the same sample.

7 In accord with the model presented in Fig. 11.1, the respondents' global evaluations of their lives (life satisfaction, happiness) and their reported affect during a particular day (a measure of experienced well-being) were substantially correlated $(r=0.38)$, but far from identical.

8 Some circumstances of life and work had different effects on evaluation and on experience. For example, divorced women reported slightly lower life satisfaction than married women, as expected. Surprisingly, the divorced women also reported slightly better affect. And a high level of time pressure at work reduced enjoyment at work significantly more than it reduced job satisfaction.

The results of this study suggest that the DRM or some variant of it can be used as a tool to assess the experienced well-being of individuals and populations and to 
identify dissociations between experienced and evaluated well-being. In the next section we propose an application of the DRM to answer the question that we posed at the beginning of this chapter, 'Who is happier, the French or the Americans?' We show that measurements of experienced well-being are needed to answer this question. We also suggest that physiological measures are needed to remove possible effects of language and culture on verbal reports of both evaluated and experienced well-being.

\section{A possible application: comparing well-being across countries}

A significant strand of well-being research has been concerned with comparisons across countries. The studies of national differences have revealed a robustly consistent pattern: the highest levels of average life satisfaction are reported by northern European democracies, there is no correlation between gross domestic product (GDP) and happiness among relatively wealthy countries, the nations of the former Soviet Empire are very dissatisfied (perhaps historically), and those of South America are surprisingly happy. Some authors (e.g. Veenhoven 1996) conclude that the problem of national differences has been solved, because a few variables account for most of the variance (see also Helliwell 2003). But others have noted that a stubborn puzzle remains: the differences between countries are too large to be plausible, especially when compared to the small effects of life circumstances (Inglehart and Rabier 1986). To illustrate this puzzle, consider the Americans and the French. The distributions of life satisfaction in the US and in France differ by about half a standard deviation. For comparison, this is also the difference of life satisfaction between the employed and the unemployed in the US, and it is almost as large as the difference between US respondents whose household income exceeds $\$ 75000$ and others whose household income is between $\$ 10000$ and $\$ 20000$ (in 1995). ${ }^{3}$ In this section we describe the implications of our analysis for research that compares the well-being of nations.

The large country effects that have been documented were observed in the answers to evaluation questions. In the present framework, the critical issue is whether the same country differences will also be found in measurements of experienced well-being. Indeed, we believe that comparisons of well-being across countries and cultures are commonly understood as referring to affect (i.e. experience). To appreciate this, imagine the following pattern of results: the population of country A reports low satisfaction with life but is consistently cheerful; the population of country B indicates high satisfaction with life but is

3 The difference in satisfaction between the unemployed and employed is based on data from waves 2 and 3 of the World Values Survey (Inglehart et al. 2003). Only wave 3 data were used in
comparing the income groups. 
generally in a sad or angry mood. Which of the conflicting measurements would be considered more compelling? We surmise that, when the goal is to compare populations, most people (and most scholars) will find a measure of experience more compelling than a measure of satisfaction as an indicator of well-being.

Is it possible to infer from the large differences in evaluated well-being that experienced well-being is also much lower in France than in the USA? We doubt it, because the sheer size of the difference seems implausible: it is hard to believe that the experienced well-being of the average employed Frenchman really matches that of the average unemployed American. Further reasons for doubt are found by comparing country effects in life satisfaction and in self-reported health status (SRHS; for a more detailed analysis see Riis, Schwarz, and Kahneman, manuscript in preparation). Among the 18 wealthiest, Western OECD (Organization of Economic Cooperation and Development) nations for which data were available, the correlation between national averages of self-reported health and of life satisfaction is $0.85^{4}$. The high correlation between health and happiness in international data sets has been interpreted as an indication of the importance of (real) health as a determinant of happiness (Helliwell 2003). However, this interpretation runs into difficulties in the set of prosperous countries, because national differences in SRHS are completely uncorrelated $(r=-0.03)$ with the most widely used objective measure of national health, adult life expectancy. For example, the French describe themselves as much less healthy than the Americans do, but they live 3 years longer.

It is fair to describe nation among developed countries, as 'reality-free'. Could the same be true as well of national differences in self-reported life satisfaction? If the French are pessimistic or grumpy in describing their (generally good) health, could they be equally grumpy in evaluating their good lives? Could the French be objectively happier than the Americans, in spite of being less satisfied? Is there a dimension of culturally determined positivity that accounts for national difference in both subjective health and life satisfaction? At this time we do not know the answers. We next sketch a research design that might help us find them.

The discussion of the design also provides an opportunity to consider a set of hypotheses that we currently consider plausible. Most importantly, we expect that

The data are from waves 2 and 3 of the World Values Survey (Inglehart $e t$ al. 2003). Data from two other wealthy, Western OECD nations, Luxembourg and New Zealand, were not available. Adding wealthy but non-Western Japan and/or Western but less wealthy Portugal does not substantially change the results. Further the same pattern of results is observed when overall (evaluative) happiness is used instead $2002 a, b)$ which is a different survey of many of the same countries. We are indebted to Richard Suzman, who drew our attention to the strikingly similar pattern of the differences between Denmark and France in the two variables. 
the variance in country averages of life satisfaction will turn out to be associated mainly with evaluation, and largely unrelated to real differences in experienced well-being. This hypothesis is consistent with results reported by Diener and his associates (2000) that imply that national differences in positivity are much smaller for ratings of specific aspects of life than for global evaluations. The same conclusion is supported by the finding, mentioned earlier, that Japanese-American students indicate lower levels of well-being than White American students in retrospective (evaluative) reports, but equivalent levels in online (experiential) reports (Oishi 2002).

A good starting point for resolving the question of national differences in experienced well-being would be to use the DRM in national samples of countries that differ in measures of life satisfaction. However, the results of such a study are unlikely to be accepted as conclusive. Although Oishi's (2002) result suggests that the reports of moment utility are less susceptible than reports of life satisfaction to the effects of cultural disposition, critics will surely question whether any affective self-description can be free of cultural influence (Wierzbicka 2004). In anticipation of such concerns, we propose a design that incorporates a physiological measure as a means of validating (and perhaps correcting) self-reports of moment utility.

\section{Can a physiological index be used to measure objective happiness?}

The background of the present proposal is the availability of a physiological index - the Davidson index of PFCA (prefrontal cortical asymmetry) - that is a valid predictor of affective responses and of approach/avoidance tendencies both within and between persons (for a review, see Davidson, Chapter 5, this volume). A recent study in an American sample also showed substantial correlations between the Davidson index and several measures of evaluated well-being (Urry et al. 2004). The advantage of this measure, of course, is that it is not susceptible to linguistic biases. It can therefore be used as an anchor for the calibration of verbal reports of both experienced and evaluated well-being.

The following data would be obtained from a French and an American sample.

1 Physiological indicators of affect, such as the Davidson index, measured under standard resting conditions. This measure has been interpreted as an indicator of a general propensity to experience positive or negative feelings (Davidson 2004).

2 Self-reports of moment utility under the same standard conditions, obtained concurrently with the physiological measure.

3 Physiological indicators of affect, measured while people are induced to focus on positive or negative features of various domains of their lives.

4 Self-reports of the intensity of the pain and of the pleasure that people experience in the same domains of life. 
5 Self-reports of life satisfaction (i.e. evaluated well-being).

6 Amount of time spent in several activities (e.g. work and leisure), measured by the DRM.

7 Self-reports of the experienced utility of these activities, measured by the DRM.

8 From measures 6 and 7, a duration-weighted summary measure of experienced well-being (objective happiness).

Next, consider what we could learn from these data. We have formulated four hypotheses.

H1 The populations do not differ in the disposition to experience positive or negative moment utility, as indicated by measure 1 , for which the issue of linguistic correspondence does not arise.

H2 The correlation between the physiological measures (1 and 3) and the selfreport measures will be positive and moderately high (a) within subjects (for measures 3 and 4), and (b) within each of the two national groups, confirming that all self-report measures are sensitive to individual differences in affective disposition.

H3 The French will report lower life satisfaction (measure 5) than the Americans. The regression lines predicting life satisfaction from the physiological indicator will have similar slopes in the two countries, but the American intercept will be higher.

H4 The differences between the populations in measures of momentary experience (measures 2 and 7) will be significantly smaller, or null (cf. Diener et al. 2000).

If these hypotheses hold-including the strong version of $\mathrm{H} 4$ - then the only source of difference between the two populations in (duration-weighted) experienced well-being is the amount of time they spend at leisure and at work. Because they have more leisure, the French would then be said to have higher well-being than the Americans. We highlight this hypothesis, not because we are particularly attached to the specific conclusion that the French are happier than the Americans, but to illustrate the possibility of significant dissociations between measures of experience and evaluation in the context of national differences.

We have discussed the simplest possible pattern of results, but more complex patterns are possible. In particular, consider the conjunction of $\mathrm{H} 1$ and the weak version of $\mathrm{H} 4$ : in the standard laboratory conditions, the physiology shows no national differences but the French report lower experienced utility. This pattern of result would suggest that the French are more cautious and less positive than the Americans even when reporting momentary mood, not only when making global judgments. The physiological measure could then be used to control for this difference in the expression of experience, particularly in the event that the weak 
version of $\mathrm{H} 4$ held, and the French reported lower experienced utility of various activities. Even more complex patterns can be anticipated. For example, it would not be particularly surprising to find that the French draw less enjoyment from work and more enjoyment from leisure than the Americans do, because of a culture that emphasizes pleasure (for empirical work relating to this possibility see Rozin et al. 1999). But the opposite result could also make sense if leisure is more appreciated by the Americans because they have less of it.

All these hypotheses are readily testable with technology currently available, and it is rather surprising that they have not yet been examined. Furthermore, technical developments that are already foreseeable will eventually allow nearly continuous non-intrusive monitoring of physiological correlates of experienced utility, as a substitute and supplement to the DRM and experience sampling. This idea would have been in the domain of science fiction in the relatively recent past, but it could turn into reality in the relatively near future.

\section{Concluding remarks}

In this chapter we have urged that the experiencing self be given due regard in well-being research. The conjunction of a powerful structural bias in favor of the remembering self and of the challenging difficulties in the measurement of experience has caused an almost exclusive emphasis on evaluated well-being. We have argued that the experiences that make the moments of life worth living deserve to be studied. We have not proposed a general answer to the puzzling question raised by Fig. 11.1: when experienced well-being and evaluated well-being diverge, what is well-being? A comprehensive solution will involve both normative and empirical issues and will be hard to find. In some cases, including the one on which we focused, the answer seems clear. If cultural differences regulate self-satisfaction but do not affect experienced well-being, the differences in satisfaction are interesting and significant, but well-being is better indexed by the quality of experience. If measurements indicate that the French are grumpy about their lives, or the Japanese are humble about theirs, while experiencing more pleasure and less pain than the American unemployed, most of us will feel more pity for the latter group. In the context of politics within a single country, on the other hand, some variations in people's satisfaction with their lives could be much more significant than variations in actual experience. Social movements arise when dissatisfied people agree on a common attribution for the source of their dissatisfaction, and also agree on what they want to do about it. We acknowledge that the scheme of Fig. 11.1 makes the study of well-being even more complicated than it was, but suggest that the complexity is real and that it is useful to admit it.

In closing, we comment on the relationship between the present analysis and the eudaemonic approach to well-being that has become highly influential in recent 
years (e.g. Ryan and Deci 2000; Ryff 1989; Ryff and Singer 1998; Seligman 2002). The eudaemonic approach draws on the Artistotelian concept of the good life, and appeals to the widely shared intuition that there is more to life than a favorable balance of pleasure and pain. Authenticity, affection, participation, efficacy, and the full utilization of human capabilities are elements of the lay concept of well-being, along with vitality and good spirits (Ryff and Keyes 1995, Seligman 2002). Eudaemonia is usually construed in this literature as a global property of an individual's life, and measured by consulting the remembering-evaluating self. But, of course, eudaemonia (or its absence) also has manifestations in the life of the experiencing self. The thrill of 'flow', the joy of intimacy, the sense of engagement in purposeful action, all can be identified and reported as characteristics of a moment. At the other extreme of the dimension, boredom and futility are also attributes of experience.

Whether or not the subjective states related to eudaemonia are 'feelings' - this is sometimes disputed - they are readily available to introspection, and they have a valence. People know when they are engaged, they know when they are killing time, and they much prefer to be engaged. The frequency and duration of these aspects of experience should therefore be included in a comprehensive description of internal life, and distinguished from the individual's self-evaluations. Indeed, it appears quite likely that experienced eudaemonia and evaluated eudaemonia will be found to have different antecedents and different consequences.

Detailed study of the experiential aspects of eudaemonia along with other types of good and bad moments will both raise and help answer several significant questions. Some of these questions are normative: how should weights be assigned to good and bad experiences that differ in kind? For example, how do experienced mastery and experienced enjoyment trade off in the measurement of well-being? Other questions are empirical. Do the activities that are most closely associated with eudaemonia have effects that spread to the experiences of more mundane situations? Do eudaemonia and other pleasures share a physiological representation in a common approach system? What is the experiential significance of different allocations of time to activities? Do different populationsperhaps the French and the Americans-create for themselves good experiences that differ in kind? There is much to learn about the well-being of the experiencing self.

\section{Acknowledgements}

The research we describe was supported by the Hewlett Foundation, the Woodrow Wilson School of Public and International Affairs at Princeton, the National Science Foundation, and the National Institute of Aging. We are grateful to Alan Krueger, David Schkade, Norbert Schwarz, and Arthur Stone for the long-term collaboration that produced many of the ideas and findings reported here. 


\section{References}

Bentham, J. (1948). An introduction to the principle of morals and legislation. Blackwell, Oxford. [Originally published in 1789.]

Broome, J. (1991). Weighing goods. Blackwell, Oxford.

Cabanac, M. (1992). Pleasure: The common currency. J. Theor. Biol. 155, 173-200.

Csikszentmihalyi, M. (1994). Flow: the psychology of optimal experience. Harper Collins, New York.

Csikszentmihalyi, M. and Larson, R. (1984). Being adolescent: conflict and growth in the teenage years. Basic, New York.

Davidson, R.J. (1992). Anterior cerebral asymmetry and the nature of emotion. Brain Cogn. 6, 245-68.

Davidson, R.J. (2004). Well-being and affective style: neural substrates and biobehavioural correlates. Phil. Trans. R. Soc. Lond. B 359, 1395-411.

Diener, E. and Seligman, M.E.P. (2004). Toward an economy of well-being. Psychol. Sci. Public Interest 5 (1), 1-31.

Diener, E. and Suh, E. (1999). National differences in subjective well-being. In Well-being: the foundations of hedonic psychology (ed. E. Diener, N. Schwarz, and D. Kahneman), pp. 434-50. Russell Sage Foundation, New York.

Diener, E., Suh, E., Lucas, R.E., and Smith, H.L. (1999). Subjective well-being: three decades of progress. Psychol. Bull. 125 (2), 276-302.

Diener, E., Scollon, C.N., Oishi, S., Dzokoto, V., and Suh, E. (2000). Positivity and the construction of life satisfaction judgments: global happiness is not the sum of its parts. J. Happiness Stud. 1 (2), 159-76.

Fredrickson, B.L. and Kahneman, D. (1993). Duration neglect in retrospective evaluations of affective episodes. J. Pers. Soc. Psychol. 65, 45-55.

Frey, B.S. and Stutzer, A. (2000). Happiness prospers in democracy. J. Happiness Stud. 1 (3), 79-102.

Helliwell, J.F. (2003). How's life? Combining individual and national variables to explain subjective well-being. Econ. Modeling 20 (2), 331-60.

Inglehart, R. and Rabier, J.R. (1986). Aspirations adapt to situations - but why are the Belgians so much happier than the French? In Research on the quality of life (ed. F.M. Andrews), pp. 1-56. Institute for Social Research, University of Michigan, Ann Arbor, Michigan.

Inglehart, R., et al. (2003). World values surveys and European values surveys, 1981-1984, 1990-1993, and 1995-1997 [Computer file]. ICPSR version. Institute for Social Research, Ann Arbor, Michigan [producer], 1999. Inter-university Consortium for Political and Social Research, Ann Arbor, Michigan [distributor].

Kahneman, D. (1999). Objective happiness. In Well-being: the foundations of hedonic psychology (ed. E. Diener, N. Schwarz, and D. Kahneman), pp. 3-27. Russell Sage Foundation, New York.

Kahneman, D. (2000). Evaluation by moments: past and future. In Choices, values and frames (ed. D. Kahneman and A. Tversky), pp. 293-308. Cambridge University Press and the Russell Sage Foundation, New York.

Kahneman, D., Fredrickson, B.L., Schreiber, C.A., and Redelmeier, D.A. (1993). When more pain is preferred to less: adding a better end. Psychol. Sci. 4, 401-5.

Kahneman, D., Wakker, P.P., and Sarin, R. (1997). Back to Bentham? Explorations of experienced utility. Q.J. Econ. 112, 375-405. 
Kahneman, D., Krueger, A.B., Schkade, D.A., Schwarz, N., and Stone, A.A. (2004a). Toward national well-being accounts. Am. Econ. Rev. 94 (2), 429-34.

Kahneman, D., Krueger, A.B., Schkade, D.A., Schwarz, N., and Stone, A.A. (2004b). A survey method for characterizing daily life experience: the day reconstruction method (DRM). Science 306 (5702), 1776-80.

Layard, R. (2005). Happiness. The Penguin Press, New York.

Marmot, M. (2004). The status syndrome. Bloomsbury, London.

Montague, P.R. and Berns, G.S. (2002). Neural economics and the biological substrates of valuation. Neuron 36 (2), 265-85.

Oishi, S. (2002). The experiencing and remembering of well-being: a cross-cultural analysis. Pers. Soc. Psychol. Bull. 28 (10), 1398-406.

Redelmeier, D. and Kahneman, D. (1996). Patients' memories of painful medical treatments: real-time and retrospective evaluations of two minimally invasive procedures. Pain 116, 3-8.

Reif, K. and Marlier, E. (2002a). Eurobarometer 44.3OVR: employment, unemployment, and gender equality, February-April 1996, Report No. 2443. Conducted by INRA (Europe), Brussels. ICPSR edition. Inter-university Consortium for Political and Social Research, Ann Arbor, Michigan [producer]. Cologne, Germany: Zentralarchiv fur Empirische Sozialforschung, Cologne, Germany/Inter-university Consortium for Political and Social Research, Ann Arbor, Michigan [distributors].

Reif, K. and Marlier, E. (2002b). Eurobarometer 443: health care issues and public security, February-April 1996, Report No. 2443. Conducted by INRA (Europe), Brussels. ICPSR edition. Inter-university Consortium for Political and Social Research, Ann Arbor, Michigan [producer]. Cologne, Germany: Zentralarchiv fur Empirische Sozialforschung, Cologne, Germany/Inter-university Consortium for Political and Social Research, Ann Arbor, Michigan [distributors].

Riis, J., Loewenstein, G., Baron, J., Jepson, C., Fagerlin, A., and Ubel, P.A. (2005). Ignorance of hedonic adaptation to hemo-dialysis: a study using ecological momentary assessment. J. Exp. Psychol. Gen. 134 (1), 3-9.

Robinson, M.D. and Clore, G.L. (2002). Episodic and semantic knowledge in emotional self-report: evidence for two judgment processes. J. Pers. Soc. Psychol. 83 (1), 198-215.

Rozin, P., Fischler, C., Imada, S., Sarubin, A., and Wrzesniewski, A. (1999). Attitudes to food and the role of food in life: comparisons of Flemish Belgium, France, Japan and the United States. Appetite 33, 163-80.

Ryan, R.M. and Deci, E.L. (2000). On happiness and human potentials: a review of research on hedonic and eudaimonic well-being. Annu. Rev. Psychol. 52, 141-66.

Ryff, C.D. (1989). Happiness is everything, or is it? Explorations on the meaning of psychological well-being. J. Pers. Soc. Psychol. 57 (6), 1069-81.

Ryff, C.D. and Keyes, C.L.M. (1995). Psychological well-being in adult life. Curr. Dir. Psychol. Sci. 69, 719-27.

Ryff, C.D. and Singer, B. (1998). The contours of positive human health. Psychol. Inquiry 9 (1), 1-28.

Sapolsky, R.M. (1999). The physiology and pathophysiology of unhappiness. In Well-being: the foundations of hedonic psychology (ed. E. Diener, N. Schwarz, and D. Kahneman), pp. 453-69. Russell Sage Foundation, New York.

Schreiber, C.A. and Kahneman, D. (2000). Determinants of the remembered utility of aversive sounds. J. Exp. Psychol. Gen. 129, 27-42. 
Seligman, M.E.P. (2002). Authentic happiness: using the new positive psychology to realize your potential for lasting fulfillment. Free Press, New York.

Shizgal, P. (1999). On the neural computation of utility: implications from studies of brain stimulation reward. In Well-being: the foundations of hedonic psychology (ed. E. Diener, N. Schwarz, and D. Kahneman), pp. 502-26. Russell Sage Foundation, New York.

Stone, A.A., Shiffman, S.S., and DeVries, M.W. (1999). Ecological momentary assessment. In Well-being: the foundations of hedonic psychology (ed. E. Diener, N. Schwarz, and D. Kahneman), pp. 61-84. Russell Sage Foundation, New York.

Sutton, S.K. and Davidson, R.J. (1997). Prefrontal brain asymmetry: a biological substrate of the behavioral approach and inhibition systems. Psychol. Sci. 8 (3), 204-10.

Urry, H., Nitschke, J.B., Dolski, I., Jackson, D.C., Dalton, K.M., Mueller, C.J., Rosenkranz, M.A., Ryff, C.D., Singer, B.H., and Davidson, R.J. (2004). Making a life worth living: neural correlates of well-being. Psychol. Sci. 15 (6), 367-72.

Veenhoven, R. (1996). Developments in satisfaction research. Soc. Indicators Res. 37 (1), 1-46.

Wierzbicka, A. (2004). 'Happiness' in cross-linguistic and cross-cultural perspective. Daedelus 133 (2), 34-43.

Wirtz, D., Kruger, J., Scollon, C.N., and Diener, E. (2003). What to do on spring break? The role of predicted, on-line, and remembered experience in future choice. Psychol. Sci. 14 (5), 520-4. 


\section{The Science of Well-Being}

Edited by

Felicia A. Huppert

Department of Psychiatry

University of Cambridge

Nick Baylis

Department of Social and Developmental Psychology

University of Cambridge

and

Barry Keverne

Department of Zoology

University of Cambridge

Contributions originating from

Philosophical Transactions of

the Royal Society, Series B.

OXFORD

UNIVERSITY PRESS

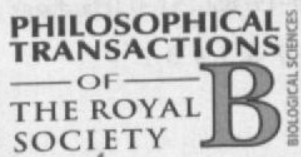

$5382 / 2005$ 
Great Clarendon Street, Oxford OX2 6DP

Oxford University Press is a department of the University of Oxford.

and education by publishing objective of excellence in research, scholarship,

Oxford New York

Auckland Cape Town Dar es Salaam Hong Kong Karachi
Kuala Lumpur Madrid Melbourne Mexico City Nairobi

New Delhi Shanghai Taipei Toronto

With offices in

Argentina Austria Brazil Chile Czech Republic France Greece

Guatemala Hungary Italy Japan Poland Portugal Singapore

South Korea Switzerland Thailand Turkey Ukraine Vietnam

Oxford is a registered trade mark of Oxford University Press

in the UK and in certain other countries

Published in the United States

by Oxford University Press Inc., New York

Chapters 6, 11, 13,15, 16 O Oxford University Press 2005

Chapters 1-5, 8-10,12, 14, 17, 19 O The Royal Society 2005

Chapter 7 C Bernard Gesch 2005

Chapter 18 American Academy of Arts and Sciences
Amstitute of Technology and the

Chapter 20 C nef 2005

The moral rights of the editors have been asserted

Database right Oxford University Press (maker)

First published 2005

All rights reserved. No part of this publication may be reproduced,

without the prior system, or transmitted, in any form or by any means,

or as expressly permitted by law, or under Oxford University Press,

reprographics rights organization, or under terms agreed with the appropriate

outside the scope of the above should bes concerning reproduction

Oxford University Press, at the address above

You must not circulate this book in any other binding or cover

and you must impose the same condition on any acquirer

British Library Cataloguing in Publication Data
Data available

Library of Congress Cataloging in Publication Data

The science of well-being / edited by Felicia A. Huppert, Nick Baylis, and Barry Keverne.

Includes bibliographical references and index.

1. Success-Psychological aspects. 2. Happiness. 3. Well-being.

$\begin{array}{lcl}\text { BF637.S8S382 } 2005 & \begin{array}{c}\text { II. Baylis, N. (Nick) } \\ \text { 155.2'5-dc22 }\end{array} & \text { III. Keverne, B. (Barry) } \\ \text { 2005015599 } & & \end{array}$

Typeset by Newgen Imaging Systems (P) Ltd., Chennai, India
Printed in Great Britain

on acid-free paper by

Biddles Ltd, King's Lynn

ISBN $0-19-856752-9$ (Pbk. : alk. paper) 978-0-19-856752-3 (Pbk. : alk. paper)
ISBN $0-19-856751-0$ (Hardback : alk. paper) $978-0-19-856751-6$ (Hardback :

10987654321 